\title{
IFS
}

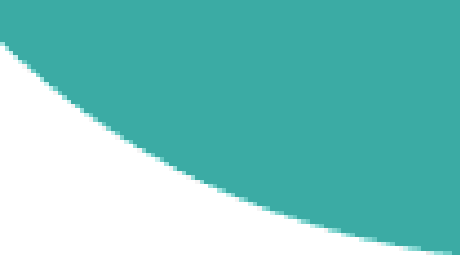

\section{WAGE SHOCKS AND CONSUMPTION VARIABILITY IN MEXICO DURING THE 1990S}

Orazio Attanasio Miguel Székely

\section{EDePo}

\section{Centre for the Evaluation of Development Policies}

THE INSTITUTE FOR FISCAL STUDIES

EWP03/02 


\title{
Wage shocks and Consumption Variability in Mexico During the 1990s
}

by

\author{
Orazio P. Attanasio and Miguel Székely`
}

\begin{abstract}
This paper presents evidence on the relationship between shocks to relative male wages, and changes in household consumption in Mexico during the 1990s decade, which is a period characterized by high volatility. Apart from performing analysis of this type for Mexico for the first time, the paper has mainly two contributions. The first is the use of alternative data sources to construct instrumental variables for wages. The second is to examine differences across four consumption categories: non-durable goods, durable goods, education and health. Our results for non-durable goods consumption reject the hypothesis that Mexican households are able to insure idiosyncratic risk. For the comparisons across consumption categories, the conclusion is that households in Mexico tend to react to temporary shocks by contracting the consumption of goods that represents longer run investment in human capital, which makes them more vulnerable in the future.
\end{abstract}

JEL Classification:

Key Words: shocks, consumption, wages, risk-sharing, synthetic panel.

31 October 2002

\footnotetext{
- Attanasio is at University College, London, the Institute of Fiscal Studies and the NBER. Székely is Under Secretary for Planning and Evaluation at the Ministry of Social Development of Mexico, and was at the Research Department, Inter American Development Bank during the first stages of this project. The authors thank Andres Montes and Erika Rascón for excellent research assistance, and INEGI for providing the data used for this work. This paper was written while Attanasio was visiting the University of Chicago, whose Department of Economics' hospitality is gratefully acknowledged. The opinions expressed in this work are the authors' and do not necessarily represents those of the institutions to which they are affiliated.
} 


\section{Introduction}

During the last 15 years Mexico underwent a number of important shocks to its economy. Some of them reflect changes in the returns to education that have also affected developed economies, albeit in slightly different manners. Others, such as the crisis that followed the peso devaluation of 1995, have been specific to Mexico and have anticipated large shocks that have affected developing countries, in particular in South East Asia, slightly later. There is now an extensive literature on the macroeconomics of these shocks. ${ }^{1}$ The evidence on the microeconomic and distributional consequences of these shocks, however, is somewhat limited, and has mainly focused on income inequality. To the best of our knowledge, there is no analysis of the evolution of inequality in recent years in Mexico that considers what is probably the most important determinant of welfare: consumption. ${ }^{2}$

In this paper we use time series of cross sectional data to study the evolution of consumption across and within education groups and relate it to changes in the distribution of wages. In doing so, we make an extensive use of synthetic cohort techniques. Our use of cohort techniques is justified not only on technical grounds (because of the absence of a true panel data) but also on theoretical grounds: as Blundell and Preston (1998) point out, meaningful welfare comparisons and measures of welfare inequality based on consumption should compare individuals at the same point in their life cycle.

The main aims of this study are four. First, we document the evolution of relative wages, across education groups and cohorts. We show that, unlike in the US in which college graduates uniformly 'win' during the 1980s and early 1990s, in Mexico the picture is more mixed. In particular, we see that for some years and some cohorts, bettereducated people fare worse than people with less education. Second, we relate the changes in relative wages to changes in relative consumption. This piece of evidence can be interpreted from a purely descriptive point of view or could be interpreted, as in

\footnotetext{
${ }^{1}$ See for instance, IDB (1995), and Hausmann and Fernandez-Arias (2000a, b).

${ }^{2}$ Some recent examples are Lustig and Székely (1998), Wodon, et.al. (2000), Morley (2000), and Eclac (2000). To our knowledge, the only recent works examining the distributional changes of shocks in Mexico are the papers by Cunningham and Maloney $(2000,2001)$, but even these papers do not include an analysis of effects on consumption.
} 
Attanasio and Davis (1996), as a test of the hypothesis of complete risk sharing across cohort and education groups. While a non-rejection of the hypothesis of full risk sharing would indeed be surprising, it constitutes a useful theoretical and practical benchmark. Third, we consider the evolution of the variance of consumption and wages. This part of the paper follows and develops work by Deaton and Paxson (1994), Attanasio and Jappelli (2001) and Attanasio et al. (2001a,b). In particular, we test the restrictions implied by full risk sharing on the evolution of the cross sectional variance of consumption. As we discuss below, these tests are complementary to those that look at the means of consumption. Fourth, in addition to non-durable consumption we also consider the effects of changes in relative wages on other variables such as durable expenditure, health expenditure and education expenditures. The aim of this exercise is more descriptive but equally important. It has been argued that poor households might react to shocks by reducing investment in human capital (health and education expenditure). As a consequence, even relatively short-lived shocks might have persistent or even permanent consequences. Moreover, it might be the case that household durable expenditures are more reactive to changes in relative wages than non-durable consumption. Our exercise provides some evidence on these issues.

The rest of the paper is organized as follows. In section 2, we summarize the theory of full risk sharing and its empirical implications. In the second part of the section, we also discuss our empirical specifications and the relevant econometric problems. In section 3 we briefly describe the data sources, as well as the evolution over time of the variables of interest. In section 4 we present our tests of risk sharing based on means and variances changes. In section 5 we consider changes in expenditure items other than non durable consumption. Section 6 concludes the paper with our interpretation of the results and some thoughts about future research.

\section{Risk Sharing and its implications.}

The assumption of full risk sharing and perfect insurance markets has received a considerable amount of attention since Townsend's (1994) seminal contribution. Such an hypothesis has two important attractions. First, it constitutes an important conceptual benchmark against which it is interesting to measure the amount of risk sharing and 
consumption smoothing achieved in real economies. Second, it is possible to characterize in a relatively simple way the implications of such a hypothesis and test them. Moreover, as we discuss below, one can construct tests that are informative about the nature of the possible violation of the null.

\subsection{Full Insurance: a Test Based on Means.}

As is well known, first best equilibrium allocations can be characterized by looking at the first order conditions of a social planner problem. The social planner is assumed to maximize the weighted utility of all agents with a set of arbitrarily fixed non-zero Pareto weights subject to a resource constraint. This dynamic optimization gives rise to the following first order condition:

$$
U_{c}\left(c_{t}^{i}\left(s_{t}\right), z_{t}^{i}\left(s_{t}\right)\right) \lambda^{i} \beta^{i}=\mu\left(s_{t}\right)
$$

where $U_{c}$ is the marginal utility of consumption for individual $i$, which is assumed to depend on its non durable consumption and, possibly, on a vector of other variables $z$, some of which might be unobservable. $\lambda^{i}$ is the Pareto-weight given by the social planner to individual $i$ in the maximization problem. Different sets of weight swill correspond to different competitive equilibria with full risk sharing. The theory is silent about what determines these weights, except in saying that they are constant over time. $\beta^{i}$ is the discount factor for individual $i$, and $\mu\left(s_{t}\right)$ is the Lagrange multiplier associated with the resource constraint at time $t$, if the state of the world is $s_{t}$. Since the work of Townsend (1994), Mace (1991) and Cochrane (1991), equation (1) has been used extensively to test the empirical implications of a model with full risk sharing. If one takes the $\log$ of equation (1) and considers it at two different time periods, one can eliminate both the discount factor and the unobserved Pareto weight. In particular, one gets:

$$
\log \left(U_{c}\left(c_{t}^{i}\left(s_{t}\right), z_{t}^{i}\left(s_{t}\right)\right)\right)-\log \left(U_{c}\left(c_{\tau}^{i}\left(s_{\tau}{ }^{\prime}\right), z_{\tau}^{i}\left(s_{\tau}{ }^{\prime}\right)\right)\right)=\mu\left(s_{t}\right)-\mu\left(s_{\tau}{ }^{\prime}\right)
$$


where $s_{\tau}{ }^{\prime}$ is the state of the world at time $\tau$. Notice that $\mathrm{t}$ and $\tau$ need not to be adjacent periods. ${ }^{3}$ If they are $k$ periods apart, one can write equation (2) as:

$$
\Delta^{k} \log \left(U_{c}\left(c_{t}^{i}\left(s_{t}\right), z_{t}^{i}\left(s_{t}\right)\right)\right)=v\left(s_{t}, s_{t-k}{ }^{\prime}\right)
$$

The main implication of equation (3) is that changes over time in the marginal utility of different individuals should be the same. The Pareto weights have been eliminated by differencing. The changes in marginal utility should be unaffected by the idiosyncratic shocks received by individuals. Full insurance means that changes in the amount of resources available to an individual over an above the aggregate change should not be reflected in changes in marginal utility. The resource constraint can be taken into account by considering either time dummies, or, as in Mace (1991) aggregate consumption. Any other variable, such as individual income, should therefore not enter equation (3).

In the absence of panel data that follow the same individuals over time, one can still test the implications of perfect risk sharing by aggregating equation (3) over individuals belonging to a given group whose membership is assumed to be fixed over time. Insurance across groups implies that the average marginal utility of consumption for different groups should change in the same way and should be unaffected by the group level shocks.

Attanasio and Davis (1996) used synthetic panels to test equation (3) by forming year of birth and education groups and following the averages for these groups over time. The synthetic panel approach has two big advantages and one disadvantage. The advantages are the possibility of testing equation (3) even in the absence of longitudinal data and the gains in power that might be obtained averaging measurement error in wages, income or whatever measures of individual resources is used over the members of a group. The disadvantage is the fact that one focuses only on the insurance across groups. By taking averages over the members of a group, one cannot say anything about the extent of risk sharing within a group.

\footnotetext{
${ }^{3}$ Moreover, if one considers many pairs of observations, the distance between the two time periods need not be the same.
} 
Assuming that the utility function is given by the following expression:

$$
U\left(c_{t}^{i}\left(s_{t}\right), z_{t}^{i}\left(s_{t}\right)\right)=\frac{\left(c_{t}^{i}\right)^{1-\gamma}}{1-\gamma} \exp \left(\theta^{\prime} z_{t}^{i}\right)
$$

equation (3), aggregated over the individuals belonging to a group $g$, will take the form:

$$
\Delta^{k} \frac{1}{\# g_{t}} \sum_{i \in g} \log \left(c_{t}^{i}\right)=\theta^{\prime} \Delta^{k} \frac{1}{\# g_{t}} \sum_{i \in g} x_{t}^{i}+d_{t}+\varepsilon_{t}^{g}
$$

where the vector $x$ includes the observable components of $z$, \#g is the sample size of group $g$, and $\varepsilon_{t}^{g}$ reflects both the unobserved components of $z$ and possible measurement error. Variables in $x$ typically include demographic factors, such as family size and composition. Given the nature of the averaging, it is likely that the residual term $\varepsilon_{t}^{g}$ has an MA(1) structure. To test the hypothesis of perfect insurance one adds to equation (5) variables that reflect changes in the amount of resources available to group $g$, such as the change in average (log) wages, and test the hypothesis that that coefficient is zero:

$$
\Delta^{k} \frac{1}{\# g_{t}} \sum_{i \in g} \log \left(c_{t}^{i}\right)=\theta^{\prime} \Delta^{k} \frac{1}{\# g_{t}} \sum_{i \in g} x_{t}^{i}+d_{t}+\phi \Delta^{k} \frac{1}{\# g_{t}} \sum_{i \in g} \log \left(w_{t}^{i}\right)+\varepsilon_{t}^{g}
$$

Notice that, given the nature of the residuals under the null of perfect insurance, unlike with the estimation of Euler equations, one does not need to rely on large $\mathrm{T}$ asymptotics. Provided that enough groups can be identified, one can estimate consistently equation $\left(5^{\prime}\right)$ using just two time periods. Notice also that if one does not want to give to $\left(5^{\prime}\right)$ the structural interpretation we have been discussing, ignoring for a moment the role played by the demographic variables $x$, the coefficient $\phi$ can be interpreted as the extent to which changes in relative wages are translated into changes into relative consumptions. 
If one wants to avoid taking differences of equation (1) one can still test the implications of the model, if enough time periods are available. To see this, take logs of equation (1) and aggregate across individuals belonging to group $g$.

$$
\frac{1}{\# g_{t}} \sum_{i \in g} \log \left(c_{t}^{i}\right)=\theta^{\prime} \frac{1}{\# g_{t}} \sum_{i \in g} x_{t}^{i}+d_{t}+\frac{1}{\# g_{t}} \sum_{i \in g} \log \left(\lambda^{i} \beta^{i}\right)+\xi_{t}^{g}
$$

The third element of the right-hand-side of equation (6) can be taken care of by group dummies. If both the number of groups and the number of time periods is large enough, we can estimate consistently equation (6) and test whether variables such as average wages appear significantly in it.

Obviously, tests based on equation (6) are tests of insurance across groups. Given the nature of the groups we consider, perhaps a rejection of the null of full insurance is not surprising. However, the tests are useful in quantifying the extent to which relative changes in some variables, such as wages, are reflected into relative changes in consumption. Moreover, the test we present below consider insurance within the groups, rather than across them.

Both in equation (5') and in equation (6), the presence of possible measurement error in wages (and the use of synthetic panels techniques on samples of limited size) induces attenuation biases. For this reason, it is necessary to use instrumental variable techniques. Attanasio and Davis (1996) used complicated lagging schemes to construct appropriate instruments for log wages and their changes in equation (6) and (5'). In this paper, we use an alternative strategy we discuss below.

Before moving to our next test, we should notice one last difference with respect to the test in Attanasio and Davis (1996) on US data. As the Mexican data are not available in every year, we cannot perform all the tests that Attanasio and Davis (1996) perform at different frequencies. Moreover, the surveys available are not equally spaced, so that strictly speaking the test we present do not refer to any specific frequency. ${ }^{4}$ However, as we mentioned in footnote 3 above, this does not matter for the validity of the test.

\footnotetext{
${ }^{4}$ Even though most surveys are two years from each other.
} 


\subsection{Full insurance: a test based on variances.}

As we mentioned above, applying the tests discussed in the previous subsection to synthetic panel data, one considers the hypothesis of perfect risk sharing across groups, while ignoring what might be happening within groups. Therefore, to complement this evidence we perform an additional test, recently proposed by Albarran and Attanasio (2001) and Attanasio et.al. (2001b) developing an idea in Deaton and Paxson (1994). ${ }^{5}$ Consider once again the log of equation (1) above, and re-write it as follows:

$$
\log \left(U_{c}\left(c_{t}^{i}\left(s_{t}\right), z_{t}^{i}\left(s_{t}\right)\right)\right)=\mu\left(s_{t}\right)-\log \left(\lambda^{i} \beta^{i}\right)
$$

Having defined groups with fixed membership, as in the analysis before, one can compute the cross sectional variance of both sides of equation (7). As the resource constraint multiplier is common across individuals it does not contribute to the cross sectional variance. The Pareto weights and the discount factors are constant over time: therefore an implication of the theory is that the cross sectional variance of the marginal utility of consumption is constant over time.

$$
\operatorname{Var}_{g}\left[\log \left(U_{c}\left(c_{t}^{i}\left(s_{t}\right), z_{t}^{i}\left(s_{t}\right)\right)\right)\right]=d_{g}
$$

where the subscript $g$ indicates that the variance is computed with the group $g$, and $d_{g}$ are group dummy variables and reflect the variance of Pareto weights and discount factors. While this implication had been noted in passing by Deaton and Paxson (1994), Albarran and Attanasio (2001) and Attanasio et al (2001b) propose and implement explicit tests of such an hypothesis.

If we assume that the utility function in equation (4), equation (7) can be written as:

$$
\operatorname{Var}_{g}\left(\log \left(c_{t}^{i}\right)+\theta^{\prime} z_{t}^{i}\right)=d_{g}
$$

\footnotetext{
${ }^{5}$ See also Attanasio and Jappelli (2001) and Jappelli and Pistaferri (2001).
} 
where the subscript $g$ indicates the fact that the variance is computed within a group Taking first differences of equation (9) one gets:

$$
\Delta \operatorname{Var}_{g}\left(\log \left(c_{t}^{i}\right)+\theta^{\prime} z_{t}^{i}\right)=0
$$

Equations (9) and (10) can be tested by adding other variables to check whether (changes in) the cross sectional variance of the marginal utility of consumption vary systematically. In particular, in the case of equation (9) we regress the level of within group marginal utility on group dummies and add to the equation the variance of $\log$ wages (or any other variable related to the shocks individual households face). The residuals in equations (9) and (10) arise from the presence of measurement error and random variation in the samples used to compute the group means and variances. ${ }^{6}$ For such a test, the presence of a large $\mathrm{T}$ is crucial, because of the presence of group dummies. In the case of equation (10), we can regress the changes in the variance of marginal utility on the changes in the variance of wages. Once again residuals arise from the presence of measurement error and sampling variation. In addition to creating the need for the use of instrumental variable, it should also be noted that, differencing equatilon (9) gives rise to $\mathrm{MA}(1)$ residuals, with all the relevant implications for efficiency.

Notice that there might be situations in which the hypothesis of perfect insurance is violated while the test just proposed does not reject the null. This is because, as is apparent from (7), the hypothesis of full insurance implies the constancy of the whole distribution of marginal utility. One can readily think of situations where the cross sectional variance of the distribution does not change, while all the other moments or the order of the observations change, therefore violating the null. ${ }^{7}$ This argument, however, is mainly an argument about the power of the proposed test.

\footnotetext{
${ }^{6}$ It should be remembered that we are using time series of cross section and that for each year-group cell we have a limited number of different households. As measurement error (and sample variation) is likely to affect both consumption and wages, one would have to instrument the estimated within group variance of wages to obtain consistent estimates. We discuss this issue in the next subsection.

${ }^{7}$ In a recent paper, Jappelli and Pistaferri (2001) notice that the full insurance hypothesis implies non mobility and, therefore, they compute Shorrocks mobility indexes to test it. This test, however, can only be used if a panel is available.
} 
To implement the test just described, one would need knowledge of the parameters $\theta$, that is of the effect that variables, such as family composition, have on the marginal utility of consumption. In the absence of such estimates from other studies, one can re-write equations (9) and (10) as follows:

$$
\begin{aligned}
& \operatorname{Var}_{g}\left(\log \left(c_{t}^{i}\right)\right)=\operatorname{Var}_{g}\left(\theta^{\prime} z_{t}^{i}\right)-\operatorname{cov}_{g}\left(\log \left(c_{t}^{i}\right), \theta^{\prime} z_{t}^{i}\right)+d_{g} \\
& \Delta \operatorname{Var}_{g}\left(\log \left(c_{t}^{i}\right)\right)=\Delta \operatorname{Var}_{g}\left(\theta^{\prime} z_{t}^{i}\right)-\Delta \operatorname{cov}_{g}\left(\log \left(c_{t}^{i}\right), \theta^{\prime} z_{t}^{i}\right)
\end{aligned}
$$

Equations ( $\left.9^{\prime}\right)$ and $\left(10^{\prime}\right)$ can be implemented using one of two alternative strategies. The first is to assume that the covariance terms are constant over time (or uncorrelated with the instruments we use), so that they can be captured by the term $d_{g}$ in equation (9') or disappear in equation (10'). Alternatively we can compute the cross sectional covariances in equation (9') and (10') and add them to the regressions we consider. In what follows, we adopted the first strategy.

This test focuses on what happens within a group, so that it is complementary to the one we discussed in the previous subsection, which tested risk sharing across groups. Depending on how groups are formed, the results of these tests could be interpreted as evidence on the nature of shocks faced by households and their insurability. Imagine for instance, to form groups, as we do later in the paper, on the basis of education and year of birth cohort. If shocks to the wage distribution across education groups are driven by technical progress and are permanent in nature, they might be harder to insure against. On the other hand, transitory shocks within an education group, might be smoothed out, if not by insurance, at least by self insurance. In such a situation we would expect to reject the null more strongly using the first test than using the second. On the other hand, if groups are defined only on the basis of year of birth cohorts, the test based on cross sectional variance should reflect not only within but also across education groups shocks and might be more likely to yield rejections. ${ }^{8}$

\footnotetext{
${ }^{8}$ Having sung the praises of this approach, however, we should stress that it does not allow for different groups to have different levels of insurance, as noted, for instance by Jalan and Ravallion (1999).
} 


\subsection{Econometric issues.}

As mentioned in section 2.1, in the presence of measurement error or limited sample size, it is necessary to instrument any additional variable one adds to equations (5'), (7), (8) or (9) to eliminate or reduce attenuation bias. Unlike Attanasio and Davis (1996), we do not use lags and leads of these variables to construct instruments: instead, we use an alternative data source. In particular, we have two time series of cross sections that are drawn from the same population. While only one contains consumption information, both contain information on male wages, as well as information on group membership. Therefore we can use the average log wage (or its change) in one survey as an instrument for the same measure in the other survey. Before doing so, however, we check that, even after removing year (and in the case of levels, group) effects, the instrument still contains explanatory power for the wage measure in the original data set. A similar argument applies to the variances.

The fact that different cells have different sample sizes, induces heteroscedasticity in our equations: larger cells will have lower variances. For this reason we weight all our equations by (the square root) of the sample size, therefore down-weighting the observations based on few observations.

The computation of the standard errors for the equation in first difference has to take into account the fact that, as the sample means are computed in levels, differencing induces MA(1) residuals. All results reported below take this feature of the residuals into account.

\subsection{Extensions: additional expenditure categories}

In section 4 , we report the results obtained applying the tests we discussed so far to data on non-durable consumption. However, utility is also likely to be affected by the consumption other commodities, such as durable goods, health or education. Therefore, we are implicitly assuming separability of the utility function between non-durable consumption and other commodities. As we have information on the expenditures on these other commodities, in principle, one could derive equations similar to (5') for the marginal utility of these items. The difficulty in following this approach lies into the fact that for these three items we do not measure consumption but expenditure. Expenditure on durables will have an effect not only on current utility but also on future utility. Health 
and education can be considered investment in human capital. For these reasons it is not possible to give the relationship between changes in relative wages and relative expenditures the structural interpretation of formal a test of perfect insurance (as we did for non durable consumption). However, it is useful as a purely descriptive device measuring how changes in relative wages are reflected in changes in relative expenditures for at least two reasons.

First, it is possible that income (wage) shocks may have little short-term impact over non-durable consumption, and still have long lasting effects on welfare through inhibiting human and physical capital accumulation. In other words, (partial) short-run smoothing of shocks might be achieved by changing investment strategies and therefore changing long-term prospects. Second, comparing whether wage shocks have larger impact on durable goods consumption, health, or education, is in itself of interest. Differences among these three items are likely if their elasticity of substitution (and that of non durable consumption) is different. That is, if households find it less painful (in the short run) to cope with changes in education and durable expenditure than with changes in non-durable consumption. More generally, individuals might find it easier to reduce the expenditure on some items rather than others. Browning and Crossley (1999) present a model in which liquidity constrained individuals will react to temporary shocks by reducing the replacement of small durables that do not have a second hand market and therefore implicit adjustment costs. Browning and Crossley (1999) present some evidence in this respect.

\section{Data}

In this paper we use two main data sources: the National Household Survey (ENIGH) which contains, among many other variables, both data on consumption and data on wages- and the National Employment Survey (ENEU) -which reports information on individual wages. This section presents the data and briefly describes the evolution of the variables used in the rest of the analysis. 


\subsection{Data sources description}

Consumption and income data at the micro economic level are available in Mexico through the National Income and Expenditure Household surveys (ENIGH). This survey is representative at the national level and is also representative of rural and urban areas separately. ENIGH surveys are available for 1989, 1992, 1994, 1996, 1998 and 2000.9 The six surveys are strictly comparable in terms of sampling frame, sampling methodology, timing (the survey is held during the last quarter of the year), recall periods, and in terms of the questionnaires that capture income and expenditures, which are the key variables of interest.

The survey considers the household as unit of observation. It contains comprehensive information on consumption, as well as a wealth of demographic and labour supply variables, including incomes and wages. The latter are available for most family members.

Most of our analysis is based on the construction of synthetic panels, that is, we form groups on the basis of features that are assumed to be constant over time and follow the means and variances of various variables for these groups over time. The main assumption that underlies this type of technique is that the membership of the group in the population of reference is constant over time. There are several reasons why this assumption might be violated. In the early and late stages of the life cycle, for instance, household formation and dissolution might be correlated with the variables of interest and this might introduce some biases. This might be a serious problem if household headship and household dissolution is linked to specific shocks. Migration and differential mortality could also bias our results.

In the analysis below we limit our sample to households whose head is between 25 and 65 years of age. This restriction is to minimize the effect of changes in sample composition due to household formation at early ages and household dissolution and differential mortality rates across socioeconomic groups at older ages. Villagomez and Zamudio (2000) show that headship rates do not change significantly until age 70

\footnotetext{
${ }^{9}$ An additional survey for 1984 is also available, but we do not use it here since the data to construct instrumental variables for wages is not available. Moreover, the sample size for the 1984 survey is considerably smaller.
} 
indicating that until that age, moving elderly individuals to extended families does not represent a strong worry. Moreover, mortality differentials are very different across education groups but less so within education groups.

As for internal migration, we work with two versions of the sample. One includes both rural and urban households, while the latter restricts the sample to the urban ones. This second restriction makes the sample compatible with our alternative data source on wages, which is only representative at the urban level. In the presence of strong migration/urbanization, the assumption of a fixed group membership would be violated as the composition of the urban areas population from which the sample is drawn would change over time. As we only use the alternative survey to construct an instrument for wages that would take care of the measurement error/ sampling error problem, we prefer to use the total sample, after checking that means and variances of log wages in the two surveys are correlated over and above year and group effects. As it turns out, however, the results are very similar, whatever sample one uses.

There is not much we can do about international migration. If individuals affected by a particularly bad shock migrate abroad, this would introduce a bias. However, we do not believe this bias would be particularly strong. Moreover, in all likelihood the bias would be towards indicating full insurance, so that our estimated effects could represent a lower bound on the actual effect.

Using the total sample, the age limitations on the household head imply samples of 11531, 10530, 12530, 13687, 10601, and 9839 for 1989, 1992, 1994, 1996, 1998 and 2000. Considering the urban sample we would have 7401, 5535, 6529, 7488, 5848 and 5402 .

Three transformations to the consumption data are performed. The first is to compute a measure of non-durable consumption by subtracting from total consumption mortgage payments, expenditure in furniture and household appliances, orthopedic and therapeutic items, vehicles and leisure goods. The second transformation is to convert non-durable consumption into adult equivalent units by using the scale proposed by 
Contreras (1996). ${ }^{10}$ The third is to deflate each observation by using the CPI. The same CPI is used for the wage data discussed below.

Individual data on wages in the ENIGH surveys is available for each income earner in the household. We restrict the sample of wage earners to males aged 25-65, which results in sample sizes of 9922, 8946, 10814, 11843, 9212, and 8339 individuals for each year in total sample and of $6350,4639,5513,6456,5,070$ and 4526 in the urban one. We consider male wages only to measure shocks to the resources available to an individual household to avoid the issue of participation and the biases that its changes could introduce in measuring average wages. The average labor force participation rate for the group males considered is $94.2 \%$ across surveys, and the average unemployment rate is only $2.1 \%{ }^{11}$

Each survey contains a detailed breakdown of all income sources including income from labor, entrepreneurial rents, interest income, property rents, transfers, and non-monetary income. To construct a comparable measure of wage incomes we use the survey questionnaire to identify the income obtained specifically as remuneration to labor earnings during the previous month, and divide it over the number of self-reported worked hours. This is deflated by the CPI to compute real hourly wages. When an individual has more than one job, we compute real hourly wages from all jobs. The procedure is applied to all labor-income earners regardless of whether they are employees or self-employed. For the self-employed, having a break down of all other income sources in the survey questionnaires reassures us of the low measurement error in wages.

As already explained, in the presence of measurement error or limited sample size, we have to construct instrumental variables for wages to eliminate or reduce attenuation bias in our empirical estimation. Fortunately, for Mexico there is an alternative source of micro data on individual wages drawn from the same population as the ENIGH, which we can use to construct instruments. The alternative source is the Urban Employment Survey (ENEU), which is held every quarter since 1987. The ENEU

\footnotetext{
${ }^{10}$ This scale was originally developed for Chile, and it is used here because an adult equivalence scale for Mexico is not available. The scale gives a weight of 1.2 to the first adult, .8 to individuals 11 years of age or older, .4 to Children ages 5-10 and .3 to children under age 5. We experiment with more flexible specifications below.

${ }^{11}$ This includes an increase in unemployment rates to about $5 \%$ for 1996 , which is the year with the highest rate.
} 
is a rotating panel with replacement every 5 quarters. Recent rounds of the ENEU have national coverage, but since the earlier ones are restricted to urban areas we restrict the sample to urban areas only in all years. The survey questionnaire is much shorter than the ENIGH questionnaire and it focuses mainly on labor market characteristics. This allows for a much larger sample size. The fourth wave of the survey, which we use here, is ideal for our purposes because it is held practically at the same dates than the ENIGH, it uses the same survey questionnaire to obtain information on wages, and uses the same sampling frame and survey methodology than the ENIGH. Recall periods for wages are also the same as in the household survey.

To construct hourly wages we follow the same procedure as the ENIGH: we identify the income item that corresponds to wages (the income obtained specifically as remuneration to labor earnings), we divide it over the number of self-reported hours, and then use the CPI to deflate the hourly wage. In this case we also include all wage earners -regardless of whether they are self-employed, informal workers or formal workers- and as with the ENIGH, we restrict the sample to males 25-65 years of age. We end up with sample sizes of 28549, 54309, 56884, 61634, 69015 and 87244.

As is common with employment surveys, the larger sample sizes increase the precision of wage estimates, but this comes at the cost of having a questionnaire with lower detail in incomes. Incomes are typically not broken down into categories, and this might introduce some measurement error into the wage data. In fact, hourly wages in the ENEU data are typically $2.8 \%$ higher than hourly wages in the ENIGH for the same sample and period of time. This discrepancy could be due to differences in the way the information is collected. We are using the ENEU survey to instrument for measurement error in the relative wages in the ENIGH. For our purposes, therefore, it is sufficient that the measurement (and sampling variation) in the two surveys are independent and that the movements in relative changes across groups are correlated between the two surveys. In the following subsection we report evidence in this sense. 
Table 1

\begin{tabular}{|c|c|c|c|c|c|c|c|c|c|c|}
\hline \multicolumn{11}{|c|}{ Average Cell Size by Cohort } \\
\hline \multirow{2}{*}{$\begin{array}{c}\text { Cohort's } \\
\text { Year of } \\
\text { Birth }\end{array}$} & \multirow[t]{2}{*}{ Age in 2000} & \multicolumn{3}{|c|}{$\begin{array}{l}\text { ENE Wage Earners } \\
\text { by Education Group }\end{array}$} & \multicolumn{3}{|c|}{$\begin{array}{c}\text { ENIGH Wage Earners } \\
\text { by Education Group }\end{array}$} & \multicolumn{3}{|c|}{$\begin{array}{l}\text { ENIGH Households } \\
\text { by Education Group }\end{array}$} \\
\hline & & Low & Medium & High & Low & Medium & High & Low & Medium & High \\
\hline 1930-1934 & $66-70$ & 1600 & 263 & 158 & 163 & 14 & 7 & 143 & 10 & 6 \\
\hline 1935-1939 & $61-65$ & 2421 & 583 & 342 & 243 & 30 & 19 & 209 & 24 & 17 \\
\hline 1940-1944 & $56-60$ & 3734 & 1222 & 777 & 374 & 82 & 53 & 321 & 70 & 43 \\
\hline $1955-1959$ & $41-45$ & 6245 & 4978 & 3899 & 672 & 476 & 239 & 484 & 307 & 178 \\
\hline 1960-1964 & $36-40$ & 5697 & 6999 & 4701 & 792 & 711 & 325 & 508 & 439 & 204 \\
\hline $1965-1969$ & $31-35$ & 4301 & 8221 & 4001 & 621 & 912 & 306 & 394 & 536 & 178 \\
\hline 1970-1974 & $26-30$ & 839 & 1776 & 732 & 157 & 241 & 67 & 80 & 107 & 29 \\
\hline
\end{tabular}

Source: Authors'calculations from ENIGH and ENE surveys

We consider the number of households based on the number of household heads.

In our analysis we divide the sample into year of birth cohorts and education groups. The division into year of birth allows following the evolution of the variables of interest over the life cycle of different groups of individuals. Dividing the sample by education groups allows us to focus on shocks to the relative price of skills.

\subsection{Descriptive analysis}

We consider three education groups, defined on the basis of the education attainment of the household head: (i) primary complete or less, (ii) some secondary education, and (iii) some higher education. ${ }^{12}$ The cohorts are formed on the basis of 5year bands: the first cohort includes household headed by individuals born between 1925 and 1929. These individuals are 60-64 years of age in the 1989 survey. The second cohort includes household heads born between 1930 and 1934, who are 55-59 years of age in 1989, and so on. Table 1 reports the average (over the different surveys) sample size of each group we consider in the two data sets.

\footnotetext{
${ }^{12}$ The Mexican schooling system is divided intothree main cycles. The first, comprising the first 6 years of formal education is labeled Primary schooling. The second cycle comprises 6 years (separated into two sub-cycles), and which is labeled Secondary. The third includes technical education or college. We have classified individuals attending any year of post-secondary schooling in the group of higher education.
} 
Table 2

\begin{tabular}{|c|c|c|c|c|c|c|c|c|}
\hline \multirow{2}{*}{$\begin{array}{c}\text { Survey } \\
\text { Year }\end{array}$} & \multicolumn{8}{|c|}{ Year of Birth of Cohort } \\
\hline & $1925-1929$ & $1930-1934$ & $1935-1939$ & $1940-1944$ & 1945-1949 & 1950-1954 & $1955-1959$ & $1960-1964$ \\
\hline \multicolumn{9}{|c|}{ Low Schooling } \\
\hline 1992 & 0.71 & 1.24 & 1.05 & 1.01 & 1.25 & 0.94 & 0.84 & 0.82 \\
\hline 1994 & 1.11 & 0.84 & 0.89 & 1.00 & 0.92 & 0.88 & 0.88 & 0.84 \\
\hline 1996 & 0.58 & 0.71 & 0.72 & 0.73 & 0.63 & 0.66 & 0.59 & 0.53 \\
\hline 1998 & 0.46 & 0.64 & 0.81 & 0.90 & 0.79 & 0.76 & 0.75 & 0.81 \\
\hline 2000 & 0.48 & 0.56 & 0.76 & 0.79 & 1.02 & 0.85 & 0.77 & 0.78 \\
\hline \multicolumn{9}{|c|}{ Medium Schooling } \\
\hline 1992 & 2.51 & 1.94 & 2.18 & 2.40 & 1.61 & 1.43 & 1.20 & 0.95 \\
\hline 1994 & 2.24 & 2.78 & 2.09 & 1.97 & 1.77 & 1.56 & 1.33 & 1.02 \\
\hline 1996 & 1.38 & 1.23 & 1.17 & 1.05 & 1.23 & 1.03 & 0.87 & 0.73 \\
\hline 1998 & 1.44 & 2.01 & 1.69 & 1.29 & 1.32 & 1.12 & 1.06 & 1.01 \\
\hline 2000 & 0.91 & 2.91 & 1.40 & 1.84 & 1.42 & 1.62 & 1.61 & 1.53 \\
\hline \multicolumn{9}{|c|}{ High Schooling } \\
\hline 1992 & 6.98 & 2.90 & 6.19 & 4.52 & 5.01 & 3.96 & 2.69 & 2.50 \\
\hline 1994 & 3.20 & 7.41 & 4.08 & 4.74 & 6.02 & 3.82 & 3.69 & 3.16 \\
\hline 1996 & 2.45 & 2.29 & 3.28 & 3.71 & 3.58 & 2.15 & 2.69 & 1.77 \\
\hline 1998 & 5.62 & 2.76 & 1.96 & 2.49 & 2.85 & 4.53 & 1.87 & 1.77 \\
\hline 2000 & 2.42 & 5.88 & 3.14 & 5.39 & 3.43 & 3.74 & 2.62 & 2.26 \\
\hline
\end{tabular}

We start our descriptive analysis by discussing how relative wages have changed across different cohort and education groups. 1996 is a particularly interesting year as it comes immediately after the 1995 peso devaluation and the subsequent deep recession that affected the Mexican economy.

Table 2 reports wage rates for different groups relative to the real wage in 1994 of low educated individuals in the cohort born between 1940 and 1944. Three features are apparent from the Table. The first, not surprising, is that for all years and all cohorts, wages and schooling levels are closely related. Individuals in the group with highest education have greater wages than those with secondary or primary, and individuals with secondary have much higher wages than those with primary. The higher-primary wage differentials vary considerably across cohorts and over time, while the higher-secondary differential is quite stable. For the higher-primary differences the greatest wage differentials are found among the youngest and oldest cohorts, and there are also variations over time. The average wage differential increased steadily in almost all cases between 1994 and 2000, which is consistent with previous evidence of increasing returns to higher education in Mexico. ${ }^{13}$

\footnotetext{
13 The evolution of returns to education in Mexico is documented in Attanasio and Székely (2001).
} 
The second feature is that for all cohorts and education groups there is a sharp decline in real wages between 1994 and 1996. This reflects the effects of the Peso crisis by the end of 1994 and which continued well into 1996. Between 1994 and 1995 GDP per capita contracted by around 7 percent in real terms, and even though the Mexican economy started its recovery in 1996, still GDP per capita was 4.2 percent lower in real terms in 1996 than in 1994. There are, however, important differences in the way different cohorts and especially different education groups were affected by this shock. Over all the worst affected group was the one with medium education, while the least affected -percent wise- was the group with the lowest level of education.

\section{Table 3}

\begin{tabular}{|c|c|c|c|c|c|c|c|c|}
\hline \multicolumn{9}{|l|}{ Survey } \\
\hline Year & 1925-1929 & 1930-1934 & 1935-1939 & 1940-1944 & 1945-1949 & $1950-1954$ & $1955-1959$ & 1960-1964 \\
\hline \multicolumn{9}{|c|}{ Low Schooling } \\
\hline 1992 & 0.90 & 1.02 & 0.93 & 0.93 & 0.84 & 0.70 & 0.81 & 0.74 \\
\hline 1994 & 1.20 & 0.99 & 1.08 & 1.00 & 0.78 & 0.80 & 0.74 & 0.76 \\
\hline 1996 & 0.76 & 0.74 & 0.77 & 0.70 & 0.62 & 0.60 & 0.65 & 0.52 \\
\hline 1998 & 0.80 & 0.80 & 0.78 & 0.76 & 0.64 & 0.65 & 0.63 & 0.64 \\
\hline 2000 & 0.56 & 0.64 & 0.71 & 0.73 & 0.76 & 0.71 & 0.68 & 0.64 \\
\hline \multicolumn{9}{|c|}{ Medium Schooling } \\
\hline 1992 & 2.22 & 1.83 & 1.99 & 1.78 & 1.74 & 1.25 & 1.36 & 1.30 \\
\hline 1994 & 2.53 & 3.00 & 2.76 & 2.18 & 1.54 & 1.30 & 1.41 & 1.34 \\
\hline 1996 & 1.62 & 1.36 & 1.09 & 1.24 & 1.03 & 1.02 & 0.89 & 1.00 \\
\hline 1998 & 1.31 & 1.44 & 1.76 & 1.13 & 0.91 & 1.15 & 0.94 & 0.87 \\
\hline 2000 & 1.11 & 1.07 & 1.28 & 1.96 & 1.31 & 1.22 & 1.17 & 1.03 \\
\hline \multicolumn{9}{|c|}{ High Schooling } \\
\hline 1992 & 3.60 & 2.49 & 3.38 & 3.09 & 3.03 & 2.36 & 2.57 & 2.78 \\
\hline 1994 & 4.10 & 4.50 & 3.34 & 3.28 & 3.77 & 2.92 & 2.54 & 2.92 \\
\hline 1996 & 2.69 & 3.93 & 2.69 & 2.10 & 2.17 & 1.67 & 2.00 & 2.01 \\
\hline 1998 & 3.87 & 2.68 & 2.27 & 2.22 & 1.91 & 1.64 & 1.53 & 1.53 \\
\hline 2000 & 1.43 & 3.00 & 2.57 & 2.27 & 2.14 & 2.06 & 1.76 & 1.32 \\
\hline
\end{tabular}

The third feature is that there are interesting differences in wage patterns across education groups not only in the reaction to the 1995 Peso crisis. While for 1992-1994 no clear pattern emerges, there are clear differences for the period 1996-1998. For individuals with secondary there is an increase in real wages between 1996 and 1998 for all cohorts, but this is not the case for the low schooling and the highly educated group. For those with low schooling there are wage contractions among the oldest two cohorts, 
and an expansion that grows the younger the cohort. For the most educated there is a decline in real wages for cohorts born between 1935 and 1949 (with the only exception of the 1950-54 cohort), and increases for the oldest two cohorts. Interestingly, real wages increase for all cohorts (but the oldest one) between 1998 and 2000 for individuals with higher education, while there is a decline among most cohorts for the least educated. This is in line with recent evidence that returns to education have increased for the most educated relative to those with lower schooling in a wide range of countries (see Behrman, Birdsall and Székely (2000)).

Table 3 reports analogous figures for non-durable consumption. The first two features of table 2 are also apparent in Table 3 . The main difference is found in consumption patterns between 1992 and 1994 and between 1996 and 1998. During 1992-1994 GDP per capita increased by about 2 percent in real terms, and this is reflected in consumption increases for practically all cohorts among households whose head had either secondary or higher education. For households whose head had only primary schooling consumption declined in 3 cohorts and increased much less than in the other education groups in the rest.

During the 1996-1998 period, where GDP per capita increased by around 4 percent in real terms, consumption of non-durable goods increased only modestly. Interestingly, the group with lowest education is the only one to register an increase across cohorts (the only exception is the cohort born between 1955 and 1959). In the group of households whose head has secondary schooling, in half of the cohorts there is a rise in consumption, and a decline in the other half. For households with the highest education there are declines in consumption in all but two cohorts. While the results for the groups of higher and primary education are in line with the wage contractions and expansions, respectively, reported in Table 2, the decline in consumption for the middle group are more surprising, since the wage expansion registered by all cohorts is not accompanied by consumption increases.

The Mexican economy continued to grow during 1999-2000 (by 3\% and 7\% respectively, in real terms), but even so, not all education groups benefited from the expansion. Among the best educated, we observe substantial increases for all but the first 
and last cohorts. For those with medium and low levels of education, there is amore mixed pattern of declines for the oldest three cohorts, and increases for the following four cohorts.

We summarize the evidence in Tables 2 and 3 with two graphs reported in Figure 1 and 2 (the numbers inside the figures correspond to the education group of each cohort). To construct Figure 1 we regressed average log consumption and wages on time and group dummies (where a group is defined by cohort and education level) and plot the residuals of the two regressions against each other. We therefore focus on relative consumption and wage levels after removing time and group effects. To construct Figure 2 , we regress changes in log consumption and log wages on year dummies and plot the residuals of the two regressions against each other. In each of the two Figures we also plot the regression line. We therefore identify the changes in relative wages and consumption after removing year effects. Both figures present a marked positive relationship between the consumption and wage residuals. In both cases, the slope is positive and statistically different from zero. In the absence of measurement error and other factors these simple figures would represent the result of the first set of tests discussed in Section 2. ${ }^{14}$ Interpreted in this way, therefore, the figures represent a first piece of evidence against the null of full insurance. More generally, one can interpret the two pictures as reflecting the extent to which changes in relative male wages (across cohort and education groups) are reflected in changes in consumption wages.

While the general message conveyed by the pictures -that there is a positive relationship between relative wage and consumption changes- is similar to that given by the evidence presented in Attanasio and Davis (1996) (AD from now on), there are three important differences. First, in the US, over the period studied by AD, highly educated individuals report relative gains year on year both in wages and consumption (that is, they would be in the upper right part of Figure 2. Here, instead, households with more education can be found also in the south-west part of the graph. This is consistent with the observation we made commenting tables 2 and 3, that in 1996 some highly educated cohorts fared worse than average. Second, at relatively high frequencies AD find no relationship between consumption and wage changes. While we cannot compute one-year

\footnotetext{
${ }^{14}$ Notice that the presence of measurement error attenuates the slope of the estimated lines.
} 
changes because of the lack of data, even at two year intervals (which would correspond to our changes- as we have roughly bi-annual data), $\mathrm{AD}$ do not find much of a relationship. Third, AD find that the size of the coefficient increases monotonically with the level of the differencing and is highest for the level specification. We find that the slope in Figure 1 and 2 is actually substantially lower for the levels than for the changes. ${ }^{15}$

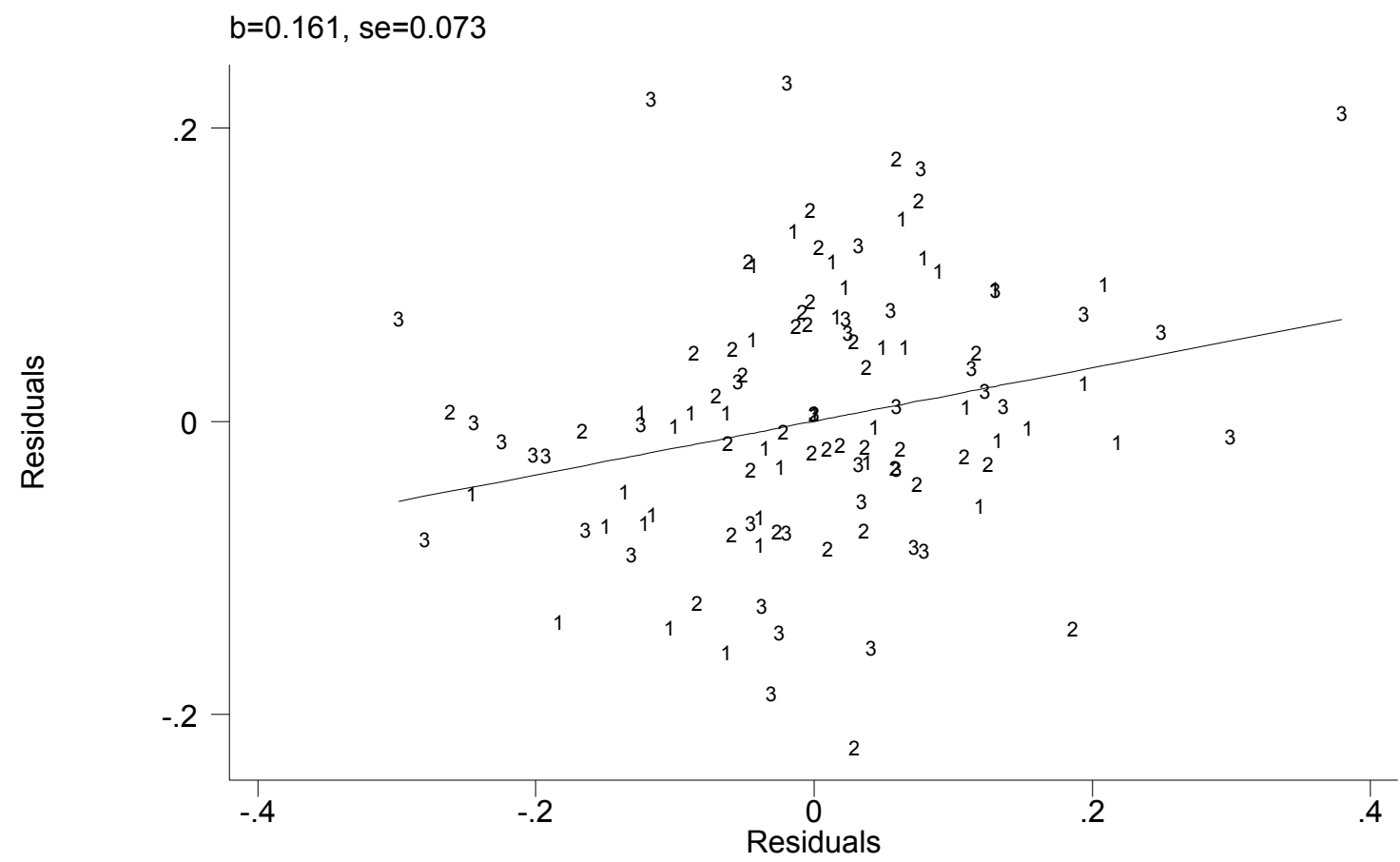

Figure 1. Relative consumption and wages

${ }^{15}$ Attanasio (2002), in a recent paper, reports that updating the AD estimates to use data up to 1998 and using an instrumenting technique similar to the one proposed in this paper, the monotonic relationship between the order of differencing and the size of the coefficient reported by AD disappears. 


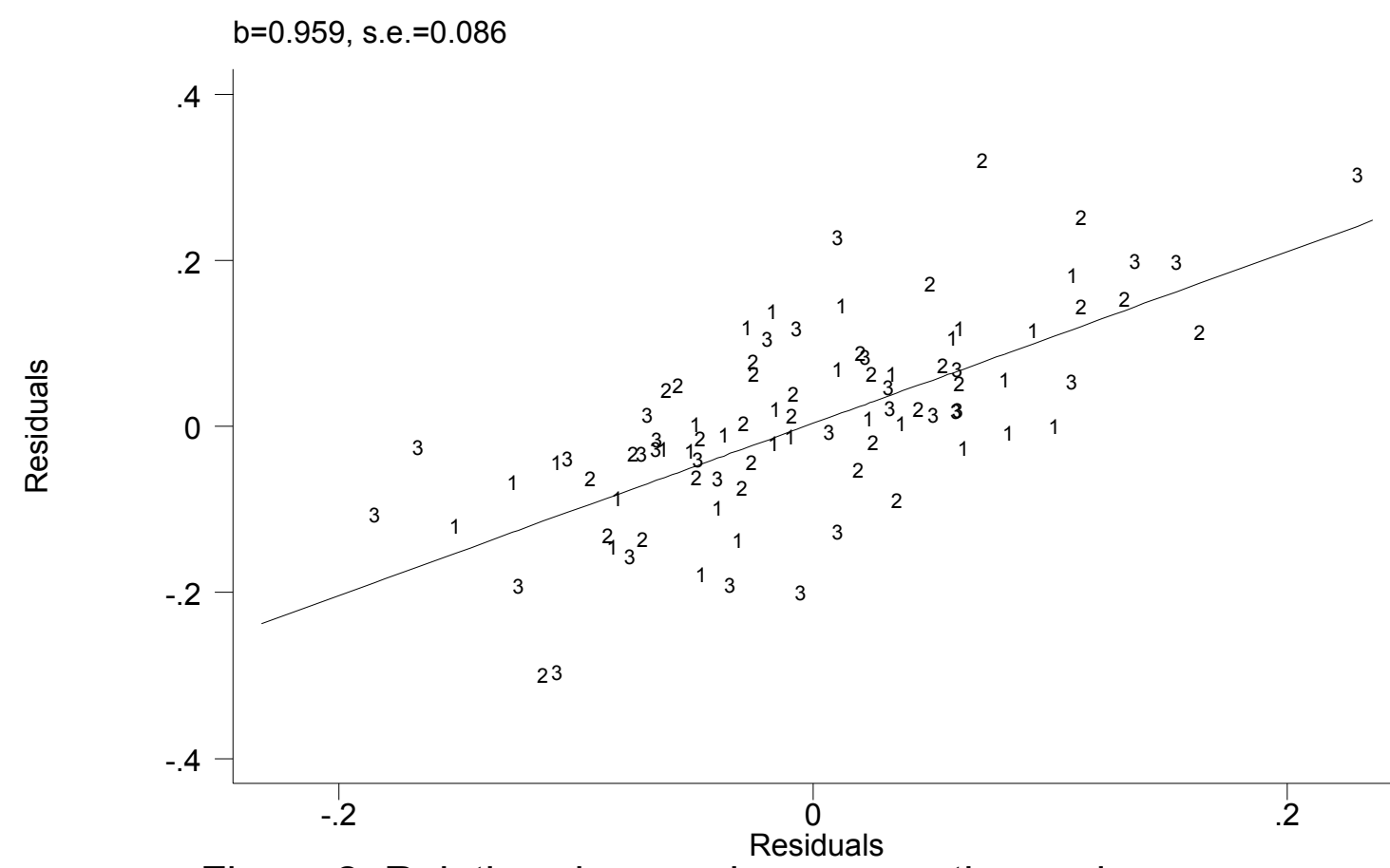

Figure 2. Relative changes in consumption and wages

As mentioned above, the presence of measurement error would bias the coefficient on wages downwards. Moreover, it is possible that family size (and possibly other variables) affect the marginal utility of consumption in ways more complex than our simple adult equivalent scale would allow. For these reasons, in what follows we perform a more formal analysis. Before doing that, however, we discuss whether we can use our alternative measure of wages as an instrument for the wages observed in our primary data source.

\subsection{How good are ENEU wages as instrument for ENIGH wages?}

In this section we study to what extent the measure of wages we get from the ENEU survey can be used as instrument for the wages in ENIGH. As the two samples are independent, the measurement error and the sample error are independent and therefore our variable satisfy the first criterion we need for a good instrument. What we also need, however, is that the movement in relative wages measured in the two surveys are also similar. 
We start by regressing, for the cells with a median age of the household head less than 60, the average log wage in the urban ENIGH on the average log wage in the ENEU. We obtain a coefficient of 1.13 with a t-value of 49.3 and an R-squared of 0.96 . This indicates that the two measures of wages are strongly correlated across groups and over time. We obtain very similar results if we use the total ENIGH. To be able to use one as an instrument for the other in our tests, however, we have to check that relative movements in wages are correlated. For this purpose, we proceed to add to the simple level regression time and group dummies. The significance of the ENEU wage in this regression is the appropriate requirement for this to be a good instrument in our level equation where time and group dummies enter (see equation (7)). Once again the results are satisfactory: the coefficient on the ENEU log wage is now 0.96 with a standard error of 0.13 if we use the urban ENIGH and 0.98 (s.e. 0.15) if we use the total ENIGH. We therefore conclude that, even after controlling for year and group effects, the ENEU and ENIGH measures of the wage are strongly correlated. As the two samples are independent, we can reliably use one measure of the wage as an instrument for the other in our level equation. Notice that this result holds even for the case in which we use two samples (the total ENIGH and the ENEU) whose population is not strictly comparable.

We then move to the consideration of the changes of average log wages. A simple regression on the urban sample gives us a coefficient of 0.96 with a standard error of 0.07 and an R-squared of 0.68 . The same regression in the total sample gives a coefficient of 0.98 (s.e. 0.09 ) and an R-squared of 0.56 in the total sample. When we add time dummies to this simple regression, the coefficients and R-squared in the ENEU wage are 0.27 (s.e. 0.10 ) in the total sample and 0.18 (s.e. 0.03 ) and R-squared of 0.26 . Therefore we conclude that both for the level and the difference specification the ENEU wage is an appropriate instrument for the ENIGH wage (and viceversa).

As we discussed above, in addition to the tests based on group means, we also perform tests based on group variances. Following a similar line of reasoning, we want to check whether the within group variances (and their changes) are correlated across groups and over time in the two databases we use. We start with the level of the variance in wages: when we regress the variance of male log wages in the ENIGH on that measured in the ENEU we obtain a coefficient of 0.47 with a standard error of 0.24 and 
an R-squared of 0.03 if we use the ENIGH total sample. If we consider the urban sample, the coefficient is 1.21 with a standard error of 0.11 and the R-square is 0.5 . As discussed above, the validity of the instrument we are considering requires the significance of the instrument in addition to the other exogenous variables we include in the structural equation. For this reason, we add group dummies to this reduced form equation for the variance of male wages in the ENIGH sample to obtain a coefficient on the variance of ENEU wages is 1.38 with a standard error of 0.31 in the total sample and of 0.81 with a s.e. of 0.26 in the urban sample. The R-squared increases to 0.79 in the total sample and to 0.66 in the urban one.

Moving to the first difference specification, regressing changes in the variance of male wages in the ENIGH on the same variable in the ENEU, we get an R-squared of 0.0002 in the total sample and 0.01 in the urban sample. In both cases, the coefficient is not statistically different from zero.

The conclusion we draw from this analysis is not as encouraging as for the reduced from for the means. In particular, we find that for the difference specification the changes in wage variances in the ENEU do not seem to be significantly correlated with changes in the wage variance for the Enigh. As for the level specification, we find that, while for the urban sample the ENEU variances seem to constitute a valid instrument for the ENIGH variances as they explain their variation, the results are borderline for the total sample. These considerations will have to be kept in mind when interpreting the results we report in section 4.2 .

\section{Results for Non-Durable Consumption}

In this section we report the results we obtain using our time series of cross sections from Mexico. In the first subsection, we report the results on the test based on means, while in the second, we report the results obtained on the test based on cross sectional variances. For both sets of results we report both the estimates obtained using the total ENIGH and its urban sub-sample. 


\subsection{Results on means}

We report two sets of results: the first is based on running the regressions in levels. These correspond to estimating equation (6). The second set of results is based on results in differences and corresponds to the estimation of equation (5'). Notice that, while equation $\left(5^{\prime}\right)$ is written in terms of first differences, it is not necessary for the two periods considered to be adjacent. Indeed it is not even necessary that the distance between subsequent periods is the same: considering the log of the equation at two arbitrary dates allows us to eliminate by differencing the unobserved Pareto weights. As the residuals are originated by measurement error, there is no reason why our test should be invalid when we consider years that are not equidistant. This is very convenient as our surveys are not equally spaced.

As a measure of consumption we use non-durable consumption per adult equivalent. The right-hand side variables, in addition to group and year dummies, include the log of family size, to allow for the possibility that our adult equivalent scheme does not capture completely changes in the needs of the households during their life cycle. We have also tried to include a polynomial in age, but the results are basically unaffected.

In the first and third column of Table 4, we report the estimates obtained by OLS using the total and urban sample respectively. In the second and four column we use the ENEU average log wage as an instrument for the measurement error in the ENIGH average log wage. In all regressions, we take into account heteroscedasticity by using cell sizes as analytic weights.

The results we obtain are a slightly surprising. First, instrumenting does not increase the size of the OLS estimates. Both in the total and (especially) in the urban samples, the point estimate of the coefficient goes down. Second, even though the OLS estimates in the first and third column indicate strong rejections of the null, the standard errors (reported under the coefficient estimates) we obtain when we use the urban sample imply that the null is not rejected. In the total sample, however, even if the point estimate goes down and the standard error doubles, the coefficient is still statistically significant. Similar results can be obtained with similar specifications, which include age of the household head as an additional control for life cycle effects and that use alternative instrumenting strategies. 
Table 4

\begin{tabular}{l|cccc}
\hline \multicolumn{5}{c}{$\begin{array}{c}\text { Means based test } \\
\text { Regressions in Levels }\end{array}$} \\
\multicolumn{5}{c}{ Dependent } \\
\hline Variable: Log \\
non-durable consumption per adult equivalent \\
variable & $(1)$ & $(2)$ & $(3)$ & $(4)$ \\
\hline Log Wage & OLS & IV & OLS & IV \\
& 0.36 & 0.282 & 0.389 & 0.193 \\
Log family & $(0.056)$ & $(0.127)$ & $(0.067)$ & $(0.134)$ \\
Size & -0.792 & -0.763 & -0.876 & -0.792 \\
R-squared & $(0.07)$ & $(0.08)$ & $(0.075)$ & $(0.093)$ \\
No of Obs. & 0.99 & 0.99 & 0.987 & 0.986 \\
\hline Sample & 114 & 114 & 114 & 114 \\
\hline Source: Authors' calculations & Total & Total & Urban & Urban \\
Note: All specifications include year and group dummies. Cell size used as analytic weights \\
\hline
\end{tabular}

In all specifications, the log of family size plays an important role, indicating the relevance of controlling for demographic effects, over and above those incorporated in the adult equivalence scales. However, exclusion of such a variable from the equation does not change substantially the results obtained on the wage coefficient. The results were also robust to the inclusion of other demographic variables, such as the number of children of various ages.

The results in Table 4 are quite different from those obtained by AD for the US in their level specification. In particular, they obtain, after instrumenting, a coefficient close to 1 . This is not the case in our specification. We discuss this and other differences at the end of this section. 
In Table 5, we report our results from estimating equation (5'). The Table is made of 4 columns. As with Table 4, the first and third report OLS estimates obtained using (changes in) ENIGH measure of log wages as a regressor, from the total and urban samples. The second and fourth columns reports IV estimates from the same samples, where the ENEU measure of average log wages is used as an instrument for ENIGH. In column 3 and 4 we use ENEU log wages as a regressor. The standard errors of this table are corrected for the presence of $\mathrm{MA}(1)$ residuals induced by firs-differencing measurement error.

Table 5

\begin{tabular}{|c|c|c|c|c|}
\hline \multicolumn{5}{|c|}{$\begin{array}{c}\text { Means based test } \\
\text { Regressions in Differences } \\
\text { Dependent Variable: } \Delta \text { Log non-durable consumption per adult } \\
\text { equivalent }\end{array}$} \\
\hline Independent variable & $\begin{array}{l}(1) \\
\text { OLS }\end{array}$ & $\begin{array}{l}\text { (2) } \\
\text { IV }\end{array}$ & $\begin{array}{l}(3) \\
\text { OLS }\end{array}$ & $\begin{array}{l}(4) \\
\text { IV }\end{array}$ \\
\hline$\Delta$ Log Wage & $\begin{array}{c}0.363 \\
(0.057)\end{array}$ & $\begin{array}{c}0.389 \\
(0.139)\end{array}$ & $\begin{array}{c}0.425 \\
(0.153)\end{array}$ & $\begin{array}{c}0.434 \\
(0.147)\end{array}$ \\
\hline$\Delta \log$ family Size & $\begin{array}{l}-0.708 \\
(0.102)\end{array}$ & $\begin{array}{l}-0.714 \\
(0.099)\end{array}$ & $\begin{array}{l}-0.871 \\
(0.116)\end{array}$ & $\begin{array}{l}-0.847 \\
(0.105)\end{array}$ \\
\hline $\begin{array}{l}\text { R-squared } \\
\text { No of Obs. }\end{array}$ & $\begin{array}{c}0.816 \\
90\end{array}$ & $\begin{array}{c}0.828 \\
90\end{array}$ & $\begin{array}{c}0.823 \\
90\end{array}$ & $\begin{array}{c}0.845 \\
90\end{array}$ \\
\hline SAMPLE & Total & Total & Urban & Urban \\
\hline \multicolumn{5}{|c|}{ Source: Authors' calculations } \\
\hline \multicolumn{5}{|c|}{$\begin{array}{l}\text { Note: All specifications include year dummies. Geometric average of adjacent cell } \\
\text { sizes used as analytic weights }\end{array}$} \\
\hline
\end{tabular}

Like the results in Table 4, the coefficients reported in Table 5 indicate strong rejections of the null hypothesis and, overall, results that are much more similar to those obtained by Attanasio and Davis (1996) for the US. Notice, in particular, that the point estimates increase when instrumenting and that the wage coefficient is statistically different from zero in all specifications. Once again, the results are robust to the instrumenting strategy and to changes in the specification.

Taken together, the results in Tables 4 and 5 indicate strong rejections of the null hypothesis that changes in relative male wages are not reflected in changes in relative 
consumption levels. These results are, however, somewhat different from those obtained by $\mathrm{AD}$. There are two main differences: on the one hand, the rejections of the null in the level specification are less strong than those reported by $\mathrm{AD}$, who for the level specification get their strongest rejections. On the other hand, the point estimates we obtain in the difference specification are a bit larger than those obtained by AD. Notice that here the comparison is a bit difficult because we do not have yearly surveys. The closest comparison that can be made is with the bi-annual differences in AD.

The differences in results can be explained by many factors. We mention three. First, it is possible that the nature of the shocks experienced by the two countries over the relevant period is very different: after all the null tests the smoothing of a particular set of shocks over a particular time period. We mentioned already that, while in the US, over the sample period considered by $\mathrm{AD}$, the best educated households are uniformly the relative winners and the least educated the relative losers, the same is not true in Mexico (see, Figures 1 and 2). Second, it might be that the level of risk sharing and the mechanisms through which it operates are very different in Mexico and the United States (which is the country analyzed in AD). Third, it is possible that the model for Mexico is somewhat mis-specified. One possibility, for instance, is that the wage rates we consider, given by earnings divided by hours, are somewhat endogenous. Indeed labor supply could be an important response to shocks and these responses could be different across countries. ${ }^{16}$ While we recognize the importance of these issues for a proper understanding of the mechanisms through which shocks are absorbed, we stress that the null we are considering implies that neither wages nor income should appear on the right hand side of our equations.

\subsection{Results on variances}

As discussed above, the tests based on the level and changes of the cross sectional variance of log consumption are complementary to those obtained using the means. Unfortunately, as a consequence of the problems discussed in Section 3.3, the IV results we obtain are not extremely informative.

\footnotetext{
${ }^{16}$ We thank a referee for stressing this issue.
} 
In Table 6, we report the OLS estimates on the total and urban sample in columns (1) and (3), while the IV results on the same samples are in columns (2) and (4). The OLS results indicate marginal rejections of the null on the total sample and a more solid one in the urban one. When one uses instrumental variables, the sign of the coefficient of both samples flips. Both estimates, however, are not statistically different from zero.

Tabla 6

\begin{tabular}{|c|c|c|c|c|}
\hline Dependent Variable & $\begin{array}{r}\text { Variaı } \\
\text { Regre } \\
\text { Variance } \\
\text { adul } \\
\end{array}$ & $\begin{array}{l}\text { based tes } \\
\text { ns in leve } \\
\text { Log non- } \\
\text { uivalent }\end{array}$ & rable co & mption per \\
\hline Independent variable & $(1)$ & $(2)$ & (3) & $(4)$ \\
\hline & OLS & IV & OLS & IV \\
\hline Variance Log Wage & $\begin{array}{c}0.102 \\
(0.052)\end{array}$ & $\begin{array}{l}-0.245 \\
(0.199)\end{array}$ & $\begin{array}{l}0.213 \\
(0.06)\end{array}$ & $\begin{array}{l}-0.344 \\
(0.259)\end{array}$ \\
\hline $\begin{array}{l}\text { Variance Log family } \\
\text { Size }\end{array}$ & $\begin{array}{l}-0.074 \\
(0.159)\end{array}$ & $\begin{array}{c}0.271 \\
(0.270)\end{array}$ & $\begin{array}{l}-0.109 \\
(0.150)\end{array}$ & $\begin{array}{l}-0.038 \\
(0.213)\end{array}$ \\
\hline R-squared & 0.517 & 0.27 & 0.702 & 0.41 \\
\hline No of Obs. & 114 & 114 & 114 & 114 \\
\hline SAMPLE & Total & Total & Urban & Urban \\
\hline
\end{tabular}

Tabla 7

\begin{tabular}{l|cccc}
\hline \multicolumn{5}{c}{$\begin{array}{c}\text { Variance based test } \\
\text { Regressions in Differences }\end{array}$} \\
\multicolumn{5}{c}{ Dependent Variable: } \\
$\begin{array}{c}\text { DVariance Log non-durable consumption per } \\
\text { adult equivalent }\end{array}$ \\
\hline Independent variable & $(1)$ & $(2)$ & $(3)$ & $(4)$ \\
& OLS & IV & OLS & IV \\
\hline$\Delta$ variance Log & 0.100 & 10.094 & 0.227 & -0.746 \\
Wage & $(0.068)$ & $(77.7)$ & $(0.069)$ & $(1.155)$ \\
$\Delta$ variance Log & 0.196 & -0.583 & 0.219 & 0.202 \\
family Size & $(0.200)$ & $(6.54)$ & $(0.152)$ & $(0.279)$ \\
R-squared & 0.041 & 0.027 & 0.153 & 0.091 \\
No of Obs. & 90 & 90 & 90 & 90 \\
\hline SAMPLE & Total & Total & Urban & Urban \\
\hline Source: Authors' calculations &
\end{tabular}


The story told by Table 7 is very similar. The coefficients obtained by OLS are remarkably similar to those obtained in Table 6. Once again, however, when using instrumental variables, the estimates change substantially and take very large standard errors. This result is particularly non-surprising, given the poor performance of the instrument used in the first step documented above.

Several interpretations of these results are possible. The first, and probably least plausible, is that shocks within groups were substantially insured: the coefficient in the total ENIGH sample is, albeit marginally significant, relatively small in size. One should be cautious about such an interpretation because of the low power afforded by the lack of an efficient instrument discussed above. Moreover, it is possible that the covariances terms in equations (9’) and (10') are not constant and bias the results we report.

\section{Results for Other Expenditure Items}

In this section we consider the relationship between relative changes in wages and relative changes in the expenditure on durable goods, health and education. As we mention in Section 2, these cannot be given the structural interpretation given to analogous results for non durable consumption. However, they are informative about which components of expenditure (if any) react to changes in wages.

Tables 8 and 9 present tests analogous to those in Tables 4 and 5, but instead of using the group mean of non-durable good consumption as a dependent variable we use the group mean of: (1) log of expenditure on durable goods, (2) log of health expenditures, and (3) $\log$ of education expenditures, respectively. ${ }^{17}$ Expenditures on durable goods and health are per adult equivalent, while expenditures on education are per school age child (children 6 to 21 years of age). For each variable, we present only IV regressions in both the total and urban samples.

Table 8 refers to the results in levels, while Table 9 reports those of the difference specification. Similarly to our results in Section 4, all regressions take into account

\footnotetext{
17 The specific items in education expenditures are education fees, books, materials, uniforms and equipment. Health expenditures include fees for all medical consults and services, medicine, hospital fees, medical tests, medical equipment, and health insurance. Durable goods consumption is constructed by deducting non-durables from total household consumption.
} 
heteroskedasticity by using cell sizes as analytical weights. Standard errors for the difference specification take into account the MA structure of the residuals. Results obtained with alternative instrumenting strategies were similar.

For none of the three expenditure categories we consider we find strong rejections of the null. This is particularly evident in the total sample, where only the t-value for the coefficient on wages in the durables equation is (barely) above 1. In the urban sample, the point estimates of the same coefficient in the durable and health equation increase considerable more than the corresponding standard error, so that the correspondent tvalue is close to 1.5 in the durable equation and close to 2 in the health equation.

The story told by Table 9, is only partly different. For durables, the point estimates of the coefficient increase substantially, taking values close to unity in both samples. The standard errors increase marginally, so that the coefficients are only marginally different from zero. The coefficients in the health expenditure equation increase, but by much less and remain, at least in the total sample, statistically insignificant. Finally, the coefficient in the education expenditure equation do not change much.

As we discussed above, it is difficult to give a structural interpretation to these coefficient. Because of the durability of the expenditures categories considered in Tables 8 and 9, we cannot interpret the right hand side of our equations as approximations to $\log$ marginal utility (or its changes). However, Tables 8 and 9 (and their comparison to Tables 4 and 5), constitute a useful descriptive tool. If we take the point estimates in the total sample at face value, for instance, they indicate that changes in relative male wages are reflected much more, in the short run, in changes in durable expenditure than in nondurables, health or education. The same is not necessarily true for the longer horizon implicitly considered by the level specifications reported in Tables 4 and 8 .

These results complement the more structural analysis of papers such as Rosenzweig and Wolpin (1993), who consider the extent to which bullocks are used as mechanism to absorb shocks in a structural model of Indian households, and that of Jacoby and Skoufias (1997) who estimate Euler equation for education expenditure (under the assumption that education can be adjusted continuously and without adjustment costs). 
Table 8

\begin{tabular}{l|cccccc}
\hline \multicolumn{7}{c}{ Mean based test } \\
\multicolumn{7}{c}{ Instrumental Variable Regressions in Levels } \\
\hline Dependent Variables: durables, health and education expenditure \\
\hline Log Wage & 0.499 & 0.774 & 0.295 & 0.779 & 0.293 & 0.379 \\
& $(0.465)$ & $(0.542)$ & $(0.382)$ & $(0.403)$ & $(0.406)$ & $(0.392)$ \\
Log family Size & -1.652 & -1.591 & -1.712 & -1.735 & -0.475 & -0.927 \\
& $(0.300)$ & $(0.374)$ & $(0.246)$ & $(0.278)$ & $(0.262)$ & $(0.271)$ \\
R-squared & 0.923 & 0.88 & 0.933 & 0.918 & 0.968 & 0.954 \\
No of Obs. & 114 & 114 & 114 & 114 & 114 & 114 \\
\hline SAMPLE & Total & Urban & Total & Urban & Total & Urban \\
\hline
\end{tabular}

Table 9

\begin{tabular}{lcccccc}
\hline \multicolumn{7}{c}{ Mean based test } \\
\multicolumn{7}{c}{ Instrumental Variable Regressions in Differences } \\
\hline Dependent Variables: durables, health and education expenditure \\
Independent variapledurables & durables & health & health & education & education \\
$\Delta$ Log Wage & 0.937 & 1.043 & 0.516 & 0.841 & 0.388 & 0.554 \\
& $(0.514)$ & $(0.702)$ & $(0.367)$ & $(0.457)$ & $(0.445)$ & $(0.479)$ \\
$\Delta$ Log family Size & -1.536 & -0.954 & -1.417 & -1.387 & -0.404 & -0.971 \\
& $(0.367)$ & $(0.454)$ & $(0.284)$ & $(0.337)$ & $(0.386)$ & $(0.354)$ \\
R-squared & 0.376 & 0.264 & 0.437 & 0.413 & 0.485 & 0.542 \\
No of Obs. & 90 & 90 & 90 & 90 & 90 & 90 \\
\hline SAMPLE & Total & Urban & Total & Urban & Total & Urban \\
\hline
\end{tabular}

\section{Conclusions}

This paper uses synthetic panel techniques to explore the relationship between shocks to relative male wages and household consumption in Mexico during the 1990s. This is a particularly interesting case, since during the decade the country experienced a large negative shock (the 1995 peso crisis) along with periods of strong growth.

Our analysis is the first, to the best of our knowledge, of the effects of relative shocks to wages on consumption in Mexico. We document the extent of the changes in relative wages over the sample period and present evidence on several components of 
consumption expenditures: namely expenditure on non-durables, durables, health and education.

The evidence on non-durable goods consumption can be interpreted as a test of the hypothesis that Mexican households are able to insure idiosyncratic risk. We consider both tests based on means and variances, which, as we discuss, are complementary, as the former could be interpreted as testing the hypothesis of risk sharing across groups, while the latter as testing risk sharing within groups. Our results on means reject the hypothesis that Mexican households are able to insure idiosyncratic risk, while those for the variances are more mixed. The tests of the variances, instead, do not yield strong rejections of the null, partly due to the low precision of the estimates. While these results might not be surprising, given the nature of the groups we consider, they are informative about the extent to which relative changes in male wages are reflected into relative changes in consumption and, presumably, welfare.

Our point estimates of the relationship between changes in relative wages and various expenditure categories, indicate that in the relative short run, changes in relative wages are more associated with changes in durable consumption than any other components. In the long run captured by the level specification we are unable to identify strong differences in the response of the components we considered, including non durable consumption expenditure. 


\section{References}

Attanasio, O.P. (2002): "Consumption and Income Inequality: What we know and what we can learn from it", Lecture to the SED meeting, New York, June 2002.

Attanasio, O. P. and S.J. Davis (1996) "Relative Wage Movements and the Distribution of Consumption", Journal of Political Economy, 104, 1227-62

Attanasio, O.P. and T. Jappelli (2001) "Intertemporal Choice and the Cross Section Variation of Marginal Utility", Review of Economics and Statistics,83, pp.13-27.

Attanasio, O.P., Berloffa, G., Blundell, R. and I. Preston (2001a): "From Wage to consumption and income inequality: Tracking shocks", Mimeo, UCL.

Attanasio, O.P., Blundell, R., Preston, I. and Z. Smith (2001b): "What shocks are insured? Evidence from the UK", Mimeo UCL.

Behrman, J., N. Birdsall and M. Székely, "Economic Reform and Wage Differentials in Latin America", RES Working Paper Series No. 435, Research Department, Inter American Development Bank, October 2000.

Blundell, R. and I. Preston (1998): "Consumption Inequality and Income Uncertainty" Quarterly Journal of Economics, 118, 603-40.

Browning, M. and T. Crossley (1999): "Shock, Stocks and Socks: Consumption Smoothing and the Replacement of Durables During an Unemployent Spell", Mimeo Mc Master University.

Cunningham, W., and Maloney, W. (2000) " Measuring Vulnerability: who Suffered in the 1995 Mexican Crisis?" Mimeo, The World Bank.

Cunningham, W., and Maloney, W. (2001) "Child Labor and Schooling Decisions" Mimeo, The World Bank.

Deaton, A. and C. Paxson (1994): "Intertemporal Choice and Inequality" Journal of Political Economy, 102, 384-94.

ECLAC, 2000. "Latin American Social Panorama", United Nations Economic Commission for Latin America, New York.

Hausmann, R. and Fernandez-Arias, E., "The Redesign of the International Financial Architecture from a Latin American Perspective: Who Pays the Bills?" Research Department Working Paper Series No. 440, Inter American Development Bank. 
Hausmann, R. and Fernandez-Arias, E., "What's Wrong with International Financial Markets" Research Department Working Paper Series No. 429, Inter American Development Bank.

Jacoby, H. G. and E. Skoufias (1997): "Risk, Financial Markets and Human Capital in A Development Country", Review of Economic Studies, 64(3), pp. 311-335.

Jalan, and M. Ravallion, (1999): “Are the Poor Less Well Insured?", Journal of Development Economics, 58 (1), pp.61-81.

Jappelli T., and L. Pistaferri (2001): "Intertemporal Choice and Consumption Mobility" Mimeo, Stanford University.

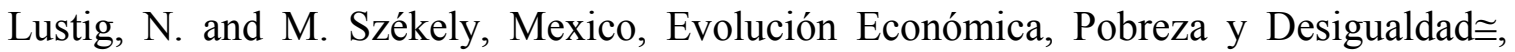
Chapter 14 in Ganuza, E., Taylor, L. and Morley, S., APolitica Macroeconomica y

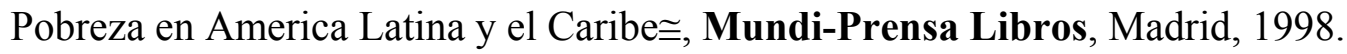

Morley, Samuel, 2000 "La distribución del Ingreso en América Latina y el Caribe". Fondo de Cultura Económica, Chile

Rosenzweig, M. and K. Wolpin (1993): "Credit Market Constraints, Consumption Smoothing and the Accumulation of Durable Production Assets in Low Income Countries: Investment in Bullocks in India", Journal of Political Economy, 101(2), pp. 223-244.

Villagomez, F.A. and A. Zamudio (2000): “A Dynamic Analysis of Household Decision Making: The Mexican Case”. IADB WP \#R-415, Washington DC.

Wodon, Q., et.al. 2000. "Poverty and Policy in Latin America and the Caribbean". The World Bank. Washington, DC. 